\title{
Rivaroxaban compared with standard anticoagulants for the treatment of acute venous thromboembolism in children: a randomised, controlled, phase 3 trial
}

\begin{abstract}
Christoph Male, Anthonie W A Lensing, Joseph S Palumbo, Riten Kumar, Ildar Nurmeev, Kerry Hege, Damien Bonnet, Philip Connor, Hélène L Hooimeijer, Marcela Torres, Anthony K C Chan, Gili Kenet, Susanne Holzhaver, Amparo Santamaría, Pascal Amedro, Elizabeth Chalmers, Paolo Simioni, Rukhmi V Bhat, Donald L Yee, Olga Lvova, Jan Beyer-Westendorf, Tina T Biss, Ida Martinelli, Paola Saracco, Marjolein Peters, Krisztián Kállay, Cynthia A Gauger, M Patricia Massicotte, Guy Young, Akos F Pap, Madhurima Majumder, William T Smith, Jürgen F Heubach*, Scott D Berkowitz, Kirstin Thelen, Dagmar Kubitza, Mark Crowther, Martin H Prins, Paul Monagle, for the EINSTEIN-Jr Phase 3 Investigators $\dagger$
\end{abstract}

\section{Summary}

Background Treatment of venous thromboembolism in children is based on data obtained in adults with little direct documentation of its efficacy and safety in children. The aim of our study was to compare the efficacy and safety of rivaroxaban versus standard anticoagulants in children with venous thromboembolism.

Methods In a multicentre, parallel-group, open-label, randomised study, children (aged 0-17 years) attending 107 paediatric hospitals in 28 countries with documented acute venous thromboembolism who had started heparinisation were assigned (2:1) to bodyweight-adjusted rivaroxaban (tablets or suspension) in a 20-mg equivalent dose or standard anticoagulants (heparin or switched to vitamin $\mathrm{K}$ antagonist). Randomisation was stratified by age and venous thromboembolism site. The main treatment period was 3 months $(1$ month in children $<2$ years of age with catheter-related venous thromboembolism). The primary efficacy outcome, symptomatic recurrent venous thromboembolism (assessed by intention-to-treat), and the principal safety outcome, major or clinically relevant nonmajor bleeding (assessed in participants who received $\geq 1$ dose), were centrally assessed by investigators who were unaware of treatment assignment. Repeat imaging was obtained at the end of the main treatment period and compared with baseline imaging tests. This trial is registered with ClinicalTrials.gov, number NCT02234843 and has been completed.

Findings From Nov 14, 2014, to Sept 28, 2018, 500 (96\%) of the 520 children screened for eligibility were enrolled. After a median follow-up of 91 days (IQR 87-95) in children who had a study treatment period of 3 months $(n=463)$ and 31 days (IQR 29-35) in children who had a study treatment period of 1 month $(n=37)$, symptomatic recurrent venous thromboembolism occurred in four (1\%) of 335 children receiving rivaroxaban and five (3\%) of 165 receiving standard anticoagulants (hazard ratio [HR] $0 \cdot 40,95 \%$ CI 0.11-1 -41). Repeat imaging showed an improved effect of rivaroxaban on thrombotic burden as compared with standard anticoagulants $(\mathrm{p}=\mathbf{0} \cdot \mathbf{0 1 2})$. Major or clinically relevant non-major bleeding in participants who received $\geq 1$ dose occurred in ten (3\%) of 329 children (all non-major) receiving rivaroxaban and in three (2\%) of 162 children (two major and one non-major) receiving standard anticoagulants (HR 1.58, 95\% CI 0.51-6.27). Absolute and relative efficacy and safety estimates of rivaroxaban versus standard anticoagulation estimates were similar to those in rivaroxaban studies in adults. There were no treatment-related deaths.

Interpretation In children with acute venous thromboembolism, treatment with rivaroxaban resulted in a similarly low recurrence risk and reduced thrombotic burden without increased bleeding, as compared with standard anticoagulants.

Funding Bayer AG and Janssen Research \& Development.

\section{Introduction}

As a result of improved treatment and survival of children with life-threatening or chronic medical conditions and increased awareness among paediatricians, venous thromboembolism is being identified more often in childhood. ${ }^{1,2}$ The incidence of venous thromboembolism in children has been estimated at 0.01-0.05 per 1000 children per year, ${ }^{3-5}$ which is $20-100$ times lower than in adults. ${ }^{6}$ Children with venous thromboembolism constitute a challenge to paediatricians because, with only a single small randomised trial available, ${ }^{7}$ there is a paucity of data about the effectiveness and harms of anticoagulants in this group. ${ }^{8}$ Furthermore, the pathophysiology of thrombosis, its anatomical distribution, and pharmacological responses to anticoagulants differ between children and adults. ${ }^{1.8}$
*Dr Heubach died in March, 2017

Department of Paediatrics, Medical University of Vienna, Vienna, Austria (Prof C Male MD); Bayer AG, Wuppertal, Germany (A W A Lensing MD, A F Pap PhD, J F Heubach MD, K Thelen PhD, D Kubitza MD); Cancer and Blood Diseases Institute, Cincinnati Children's Hospital Medical Center (J S Palumbo MD); Department of Pediatrics, University of Cincinnati College of Medicine, Cincinnati, OH, USA

(J $S$ Palumbo MD); Nationwide Children's Hospital, The Ohio State University, Columbus, OH, USA (R Kumar MD); Kazan State Medical University, Russia (I Nurmeev MD); Riley Hospital for Children at IU Health, Indianapolis, IN, USA (K Hege MD); M3C-Necker Enfants malades, Université Paris Descartes, Sorbonne Paris Cité, Paris, France (Prof D Bonnet MD); The Noah's Ark Children's Hospital for Wales, Cardiff, UK (P Connor MD); Department of Hematology and Oncology, University Medical Center Groningen, Beatrix Children's Hospital, Groningen, Netherlands

(HL Hooimeijer MD); Department of Hematology and Oncology, Cook Children's Medical Center, Fort Worth, TX, USA (M Torres MD); McMaster Children's Hospital, 
Hamilton, ON, Canada (Prof A K C Chan MD); Sackler Faculty of Medicine, Tel Aviv University, Tel Aviv, The Israeli National Hemophilia Center and Thrombosis Unit, and The Amalia Biron Thrombosis Research Institute, Sheba Medical Center, Tel Hashomer, Israel (Prof G Kenet MD); Charité University Medicine,

Department of Paediatric Haematology and Oncology, Berlin, Germany

(S Holzhauer MD); Haemostasis and Thrombosis Unit, Department of Haematology, University Hospital Vall d'Hebron, Barcelona, Spain (A Santamaría, MD); Paediatric and Congenital Cardiology Department, M3C Regional Reference Centre, Montpellier University Hospital,

PhyMedExp, INSERM, CNRS, Montpellier, France

(P Amedro MD); Royal Hospital for Children, Glasgow, UK

(E Chalmers MD); Thrombotic and Haemorrhagic Diseases

Unit, Department of Medicine (DIMED), Padua University Hospital, Padua, Italy (Prof P Simioni MD); Ann \& Robert H Lurie Children's Hospital of Chicago, Feinberg School of Medicine,

Northwestern University, IL,

USA (RV Bhat MD); Baylor

College of Medicine and Texas Children's Hospital,

Houston, TX, USA (D L Yee MD); Ural Federal University and Ural

State Medical University, Yekaterinburg, Russia

(O Lvova MD); Department of

Medicine I, Division of Haematology and

Haemostaseology, University

Hospital "Carl Gustav Carus" Dresden, and King's Thrombosis Service,

Department of Haematology,

King's College London, UK

(ProfJ Beyer-Westendorf MD);

Department of Haematology,

The Newcastle upon Tyne

Hospitals NHS Foundation

Trust Newcastle Upon Tyne, UK

(TT Biss MD); Fondazione IRCCS Ca' Granda - Ospedale

Maggiore Policlinico, A Bianchi Bonomi Haemophilia and

Thrombosis Centre, Milan, Italy (I Martinelli MD); University Hospital Città della Salute $\mathrm{e}$ della Scienza, Turin, Italy

(P Saracco MD); Department of Paediatric Haematology, Emma Children's Hospital, University Medical Centres,

\section{Research in context}

\section{Evidence before this study}

Venous thromboembolism in children is predominantly seen in children with severe underlying medical or surgical problems. Guidelines for treatment of paediatric venous thromboembolism rely on low level paediatric evidence or are extrapolated from adult evidence. We searched PubMed for the period Jan 1, 1990, to Jan 1, 2019, using the terms "anticoagulants", "heparin", "vitamin K antagonist", "DOAC", "children", "pediatric", "treatment", "venous thromboembolism", and "randomised study". The single randomised trial which we identified was done in children with venous thromboembolism almost 20 years ago and was prematurely stopped after inclusion of only 76 children owing to slow enrolment. The trial compared intravenous unfractionated heparin followed by warfarin with subcutaneous administrations of the low molecular weight heparin reviparin followed by warfarin. Recurrent thromboembolism occurred in four $(10 \%)$ of 40 children and major bleeding occurred in five $(13 \%)$ of 40 children treated with unfractionated heparin and warfarin, compared with two $(6 \%)$ of 36 and two $(6 \%)$ of 36 children treated with reviparin and warfarin. Treatment of venous thrombosis in children is further limited by the absence of paediatric anticoagulant formulations, and the need for parenteral administration and for regular laboratory monitoring

Fixed-dose treatment with the direct oral anticoagulant rivaroxaban is efficacious and safe for treatment of venous thromboembolism in adults. In the EINSTEIN-Jr phase 1 and 2 studies, bodyweight-adjusted rivaroxaban dose regimens with

Fixed-dose rivaroxaban is effective for treatment of venous thromboembolism in adults and is associated with a lower risk of major bleeding as compared with the traditional combination of heparin followed by a vitamin $\mathrm{K}$ antagonist. ${ }^{9-11}$ In collaboration with the European and US regulatory agencies, a strategy was developed to evaluate rivaroxaban for treatment of venous thromboembolism in children. ${ }^{12,13}$ In the EINSTEIN-Jr phase 1 and 2 studies, ${ }^{14-18}$ bodyweight-adjusted rivaroxaban dose regimens were established for children aged between birth to 17 years that matched the exposure range in adults younger than 45 years treated with rivaroxaban $20 \mathrm{mg}$ once-daily. ${ }^{19}$

Anticoagulants given to young children are mostly parenterally administered, ${ }^{8}$ and are limited to dosage forms designed for adults that often need pharmaceutical manipulation to achieve the required paediatric dose.,20 However, manipulations might affect the stability and bioavailability of these drugs, and are prone to dosing errors, thereby potentially jeopardising safety and efficacy. ${ }^{20}$ To avoid these manipulations, as well as parenteral administration of anticoagulants, a rivaroxaban oral suspension was developed, which has similar pharmacokinetic properties to the tablet formulation. ${ }^{17,18}$ This suspension will enable precise dosing and easier administration, especially in young children. tablets or a newly developed oral suspension have been established for children aged between birth and 18 years matching the exposure range of young adults treated with rivaroxaban $20 \mathrm{mg}$ once daily.

\section{Added value of this study}

The EINSTEIN-Jr phase 3 study is the first completed trial of a direct oral anticoagulant in children and the largest trial of anticoagulant treatment ever done in children. The results show that treatment of children with venous thromboembolism with bodyweight-adjusted rivaroxaban tablets or suspension resulted in a similarly low recurrence risk and reduced thrombotic burden without increased bleeding compared with standard anticoagulants.

Implications of all the available evidence

Study outcomes and relative efficacy and safety of rivaroxaban versus standard anticoagulants in children were similar to those observed in adult studies on rivaroxaban treatment. Given this similarity of clinical course of venous thromboembolism, and relative treatment effects, the results of the EINSTEIN-Jr studies can be interpreted in the context of the body of evidence from adults, which overall provides sufficient evidence to inform practical use of rivaroxaban in children. The availability of the rivaroxaban suspension formulation will obviate the need for long-term treatment of children with parenteral anticoagulants.

We aimed to compare the efficacy and safety of bodyweight-adjusted paediatric rivaroxaban dose regimens with those of standard anticoagulants in children with acute venous thromboembolism who had completed at least 5 days of initial heparinisation.

\section{Methods \\ Study design and participants}

A randomised, open-label, phase 3 study was done comparing the efficacy and safety of rivaroxaban with those of standard anticoagulants for treatment of venous thromboembolism. The main study treatment period was 3 months, with the exception of children younger than 2 years who had catheter-related venous thromboembolism, for whom it was 1 month. ${ }^{21}$

Elligible children aged 0-17 years were recruited from 107 paediatric hospitals in 28 countries. The trial design has been published previously. ${ }^{21}$ The trial was done to meet the objectives outlined in both the European Medicines Agency Paediatric Investigational Plan, ${ }^{12}$ and the Food and Drug Administration (FDA) Paediatric Research Equity Act Post-Marketing Requirements, ${ }^{13}$ with the study window set at 4 years of age. The protocol ${ }^{22}$ was approved by the institutional review board at each participating centre. Written permission from a parent or guardian and, when 
appropriate, child assent, were obtained. An independent data monitoring committee periodically reviewed the study outcomes (appendix p 6). An independent adjudication committee, whose members were unaware of study group assignment, evaluated the initial diagnosis, all suspected outcomes, and repeat thrombosis imaging tests.

Children aged between birth to 17 years were potentially eligible if they had objectively confirmed venous thromboembolism for which heparin treatment was initiated. Children younger than $0 \cdot 5$ years were required to have a gestational age at birth of at least 37 weeks, a bodyweight above $2600 \mathrm{~g}$, and to have had oral feeding for at least 10 days. Children were ineligible if they had active bleeding or were at a high risk of bleeding contraindicating anticoagulant therapy, had a platelet count of less than $50 \times 10^{9}$ cells per $\mathrm{L}$, hepatic disease associated with a coagulopathy, severe renal impairment, or a life expectancy less than 3 months. The full list of eligibility criteria is provided in the appendix (p 8). The individual risk factor profile for venous thromboembolism was centrally classified as unprovoked, or provoked by a permanent or transient risk factor, or both. ${ }^{22}$

Children commenced enrolment once the preceding phase 2 study had identified a rivaroxaban regimen for their bodyweight that matched the exposure in young adults treated with $20 \mathrm{mg}$ rivaroxaban once-daily. The phase 2 study initially evaluated children aged 12-17 years followed by children aged 6-11 years, 2-5 years, and younger than 2 years. ${ }^{18}$ Consequently, inclusion in the current study occurred in the same order.

\section{Randomisation and masking}

Using an interactive online response system and permuted blocks of three, we randomly assigned children in a 2:1 ratio to receive open-label rivaroxaban or standard anticoagulants. Randomisation was stratified according to the age groups and site of venous thromboembolism (ie, cerebral vein or sinus thrombosis, or thrombosis of the caval, renal, portal, or jugular vein), and catheter-related venous thrombosis, and thrombosis of the lower or upper extremity (including subclavian and axillary vein), lungs, right heart, in the absence of a venous catheter. This trial was open-label, and investigators and patients and their families were aware of treatment assignment.

\section{Procedures}

Following completion of 5-9 days of anticoagulation with unfractionated heparin, low molecular weight heparin, or fondaparinux, children were randomised to standard anticoagulants or rivaroxaban. Children allocated to rivaroxaban received a bodyweight-adjusted $20 \mathrm{mg}$ equivalent dose, given once-daily (for bodyweights of $\geq 30 \mathrm{~kg}$ ), twice-daily (for bodyweights of $12-<30 \mathrm{~kg}$ ), or thrice-daily for bodyweights of, $<12 \mathrm{~kg}$ ) (appendix $\mathrm{p} \mathrm{9).}$ Rivaroxaban was administered as immediate release filmcoated tablets available in strengths of 5, 10, 15, or $20 \mathrm{mg}$, or as suspension. The suspension was provided as granules in a bottle that had to be filled with water to a concentration of $1 \mathrm{mg} / \mathrm{mL}$ and was administered by means of a standardised dosing device. Initially, rivaroxaban was administered as tablets, but once recruitment of children younger than 6 years of age was allowed, all newly randomised children received the suspension. Rivaroxaban was administered with an age-appropriate serving of fluid given with or shortly after a meal.

Children in the standard anticoagulants group continued with heparin treatment or switched to a vitamin $\mathrm{K}$ antagonist, ${ }^{21}$ at the discretion of the treating physician. Standard anticoagulation was given at therapeutic doses, according to international guidelines. ${ }^{8,21}$

At monthly follow-up visits, a structured questionnaire was used to elicit signs and symptoms of study outcomes. At the end of the main treatment period, repeat thrombosis imaging was done, provided no additional ionising radiation or general anaesthesia was required. Patients and their guardians were instructed to report to the study centre if symptoms suggestive of recurrent venous thromboembolism or bleeding developed. Objective testing for confirmation was required for children with suspected outcome events.

\section{Outcomes}

The primary efficacy outcome was symptomatic recurrent venous thromboembolism, assessed by the central independent adjudication committee. The principal safety outcome was the composite of overt major and clinically relevant non-major bleeding (appendix p 10). ${ }^{23,24}$ Repeat imaging tests were compared with baseline and results were classified as normalised, (ie, no residual thrombus observed), improved (ie, thrombus still present but partly recanalised or involving less venous segments), no relevant change (ie, not recanalised and similar in extent), or deteriorated (ie, new venous segment involved; appendix p 11). ${ }^{21}$ Secondary outcomes were the composite of recurrent venous thromboembolism and deterioration on repeat imaging, and the composite of recurrent venous thromboembolism and major bleeding (net clinical benefit). In a separate publication, the pharmacokinetic and pharmacodynamic analyses in children belonging to the rivaroxaban group will be reported in detail.

\section{Statistical analysis}

A properly powered non-inferiority study was not feasible owing to the low incidence of venous thromboembolism in children and lack of well-documented information on recurrence and treatment effect with standard anticoagulants in children. Hence, there was no formal a priori sample size calculation.

Efficacy analyses included all randomised children, whereas safety analyses included those who had received at least one dose of study medication. Efficacy outcomes were considered during the main treatment period, whereas safety outcomes were considered for the main treatment period during the time from administration of ocation Academic Medical Centre, Amsterdam, Netherlands (M Peters MD) Department of Paediatric Haematology and Stem Cell Transplantation, Central Hospital of Southern Pest, National Institute of Haematology and Infectious Diseases, Budapest, Hungary (K Kállay MD); Nemours Children's Specialty Care, Jacksonville, FL, USA (C A Gauger MD); Department of Paediatrics, University of Alberta, Edmonton, AB, Canada (M P Massicotte MD); Children's Hospital Los Angeles, University of Southern California Keck School of Medicine, Los Angeles, USA (Prof G Young MD); Bayer, Whippany, NJ, USA (M Majumder $\mathrm{PhD}$ WT Smith MD, SD Berkowitz MD); Department of Medicine, McMaster University, Hamilton, ON, Canada (Prof M Crowther MD); Department of Clinical Epidemiology and Medical Technology Assessment, Maastricht University Medical Centre, Maastricht, Netherlands (Prof M H Prins MD); and Department of Clinical Haematology, Royal Children's Hospital, Haematology Research Murdoch Children's Research Institute, Department of Paediatrics, University of Melbourne, VIC, Australia (Prof P Monagle MD)

Correspondence to: DrChristoph Male, Department of Paediatrics, Medical University of Vienna, Waehringer Guertel 18-20, A-1090 Vienna, Austria christoph.male@meduniwien. ac.at 


\begin{tabular}{|c|c|c|c|c|c|c|c|c|c|c|}
\hline & \multicolumn{2}{|c|}{ Age birth-23 months } & \multicolumn{2}{|l|}{ Age 2-5 years } & \multicolumn{2}{|c|}{ Age 6-11 years } & \multicolumn{2}{|l|}{ Age $12-17$ years } & \multicolumn{2}{|l|}{ Total } \\
\hline & $\begin{array}{l}\text { Rivaroxaban } \\
(n=37)\end{array}$ & $\begin{array}{l}\text { Comparator } \\
(n=17)\end{array}$ & $\begin{array}{l}\text { Rivaroxaban } \\
(n=47)\end{array}$ & $\begin{array}{l}\text { Comparator } \\
(n=22)\end{array}$ & $\begin{array}{l}\text { Rivaroxaban } \\
(n=67)\end{array}$ & $\begin{array}{l}\text { Comparator } \\
(n=34)\end{array}$ & $\begin{array}{l}\text { Rivaroxaban } \\
(n=184)\end{array}$ & $\begin{array}{l}\text { Comparator } \\
(n=92)\end{array}$ & $\begin{array}{l}\text { Rivaroxaban } \\
(\mathrm{n}=335)\end{array}$ & $\begin{array}{l}\text { Comparator } \\
(\mathrm{n}=165)\end{array}$ \\
\hline \multicolumn{11}{|l|}{ Sex } \\
\hline Female & $15(41 \%)$ & $6(35 \%)$ & $24(51 \%)$ & $9(41 \%)$ & $24(36 \%)$ & $15(44 \%)$ & $97(53 \%)$ & $55(60 \%)$ & $160(48 \%)$ & $85(52 \%)$ \\
\hline Male & $22(59 \%)$ & $11(65 \%)$ & $23(49 \%)$ & $13(59 \%)$ & $43(64 \%)$ & $19(56 \%)$ & $87(47 \%)$ & $37(40 \%)$ & $175(52 \%)$ & $80(48 \%)$ \\
\hline \multicolumn{11}{|l|}{ Race } \\
\hline Caucasian & $22(59 \%)$ & $11(65 \%)$ & $40(85 \%)$ & $17(77 \%)$ & $51(76 \%)$ & $23(68 \%)$ & $158(86 \%)$ & $73(79 \%)$ & $271(81 \%)$ & $124(75 \%)$ \\
\hline Asian & $6(16 \%)$ & $3(18 \%)$ & $2(4 \%)$ & $2(9 \%)$ & $9(13 \%)$ & $1(3 \%)$ & $3(2 \%)$ & $2(2 \%)$ & $20(6 \%)$ & $8(5 \%)$ \\
\hline Black & $3(8 \%)$ & 0 & $1(2 \%)$ & 0 & $2(3 \%)$ & $4(12 \%)$ & $7(4 \%)$ & $8(9 \%)$ & $13(4 \%)$ & $12(7 \%)$ \\
\hline Other or not disclosed & $6(16 \%)$ & $3(18 \%)$ & $4(9 \%)$ & $3(14 \%)$ & $5(7 \%)$ & $6(18 \%)$ & $16(9 \%)$ & $10(11 \%)$ & $31(9 \%)$ & $21(13 \%)$ \\
\hline Bodyweight, range, $\mathrm{kg}$ & $2 \cdot 7-15$ & $3 \cdot 0-14$ & $10-25$ & $8 \cdot 6-22$ & $17-71$ & $19-72$ & $27-135$ & $32-160$ & $2 \cdot 7-135$ & $3 \cdot 0-160$ \\
\hline \multicolumn{11}{|c|}{ Index venous thrombosis location } \\
\hline $\begin{array}{l}\text { Cerebral vein or sinus } \\
\text { thrombosis }\end{array}$ & $4(11 \%)$ & $5(29 \%)$ & $23(49 \%)$ & $12(55 \%)$ & $31(46 \%)$ & $17(50 \%)$ & $16(9 \%)$ & $9(10 \%)$ & $74(22 \%)$ & $43(26 \%)$ \\
\hline $\begin{array}{l}\text { Catheter-related venous } \\
\text { thromboembolism }\end{array}$ & $26(70 \%)$ & $11(65 \%)$ & $19(40 \%)$ & $7(32 \%)$ & $16(24 \%)$ & $8(24 \%)$ & $29(16 \%)$ & $11(12 \%)$ & $90(27 \%)$ & $37(22 \%)$ \\
\hline Lower extremities & $13 / 26(50 \%)$ & $9 / 11(82 \%)$ & $6 / 19(32 \%)$ & $4 / 7(57 \%)$ & $2 / 16(13 \%)$ & $2 / 8(25 \%)$ & $1 / 29(3 \%)$ & 0 & $22 / 90(24 \%)$ & $15 / 37(41 \%)$ \\
\hline $\begin{array}{l}\text { Caval, renal, or portal } \\
\text { vein }\end{array}$ & 0 & $1 / 11(9 \%)$ & 0 & 0 & $1 / 16(6 \%)$ & 0 & $1 / 29(3 \%)$ & 0 & $2 / 90(2 \%)$ & $1 / 37(3 \%)$ \\
\hline Right heart & $1 / 26(4 \%)$ & 0 & $2 / 19(11 \%)$ & $1 / 7(14 \%)$ & $2 / 16(13 \%)$ & $2 / 8(25 \%)$ & $2 / 29(7 \%)$ & $1 / 11(9 \%)$ & $7 / 90(8 \%)$ & $4 / 37(11 \%)$ \\
\hline Upper extremities* & 0 & 0 & $4 / 19(21 \%)$ & 0 & $5 / 16(31 \%)$ & $2 / 8(25 \%)$ & $18 / 29(62 \%)$ & $6 / 11(55 \%)$ & $27 / 90(30 \%)$ & $8 / 37(22 \%)$ \\
\hline Jugular vein & $12 / 26(46 \%)$ & $1 / 11(9 \%)$ & $7 / 19(37 \%)$ & $2 / 7(29 \%)$ & $6 / 16(38 \%)$ & $2 / 8(25 \%)$ & $7 / 29(24 \%)$ & $4 / 11(36 \%)$ & $32 / 90(36 \%)$ & $9 / 37(24 \%)$ \\
\hline $\begin{array}{l}\text { Non-catheter-related } \\
\text { venous thromboembolism }\end{array}$ & $7(19 \%)$ & $1(6 \%)$ & $5(11 \%)$ & $3(14 \%)$ & $20(30 \%)$ & $9(26 \%)$ & $139(76 \%)$ & $72(78 \%)$ & $171(51 \%)$ & $85(52 \%)$ \\
\hline Lower extremities & $2 / 7(29 \%)$ & 0 & $3 / 5(60 \%)$ & $1 / 3(33 \%)$ & $9 / 20(45 \%)$ & $6 / 9(67 \%)$ & $76 / 139(55 \%)$ & $31 / 72(43 \%)$ & $90 / 171(53 \%)$ & $38 / 85(45 \%)$ \\
\hline $\begin{array}{l}\text { Caval, renal, or portal } \\
\text { vein }\end{array}$ & $4 / 7(57 \%)$ & 0 & $1 / 5(20 \%)$ & 0 & $3 / 20(15 \%)$ & $1 / 9(11 \%)$ & $2 / 139(1 \%)$ & 0 & $10 / 171(6 \%)$ & $1 / 85(1 \%)$ \\
\hline Right heart & 0 & 0 & 0 & 0 & $1 / 20(5 \%)$ & 0 & $1 / 139(1 \%)$ & $1 / 72(1 \%)$ & $2 / 171(1 \%)$ & $1 / 85(1 \%)$ \\
\hline Pulmonary & 0 & 0 & 0 & $2 / 3(67 \%)$ & $3 / 20(15 \%)$ & 0 & $46 / 139(33 \%)$ & $29 / 72(40 \%)$ & 49/171 (29\%) & $31 / 85(36 \%)$ \\
\hline Upper extremities* & 0 & $1 / 1(100 \%)$ & 0 & 0 & $2 / 20(10 \%)$ & $2 / 9(22 \%)$ & $9 / 139(6 \%)$ & 9/72 (13\%) & $11 / 171(6 \%)$ & $12 / 85(14 \%)$ \\
\hline Jugular vein & $1 / 7(14 \%)$ & 0 & $1 / 5(20 \%)$ & 0 & $2 / 20(10 \%)$ & 0 & $5 / 139(4 \%)$ & $2 / 72(3 \%)$ & $9 / 171(5 \%)$ & $2 / 85(2 \%)$ \\
\hline $\begin{array}{l}\text { Symptomatic venous } \\
\text { thromboembolism }\end{array}$ & $20(54 \%)$ & $13(76 \%)$ & $32(68 \%)$ & $15(68 \%)$ & $50(75 \%)$ & $26(76 \%)$ & $169(92 \%)$ & $82(89 \%)$ & $271(81 \%)$ & $136(82 \%)$ \\
\hline $\begin{array}{l}\text { First episode of venous } \\
\text { thromboembolism }\end{array}$ & $37(100 \%)$ & $16(94 \%)$ & $44(94 \%)$ & $21(95 \%)$ & $65(97 \%)$ & $32(94 \%)$ & $180(98 \%)$ & $83(90 \%)$ & $326(97 \%)$ & $152(92 \%)$ \\
\hline Initial heparinisation† & $37(100 \%)$ & $17(100 \%)$ & $47(100 \%)$ & $22(100 \%)$ & $67(100 \%)$ & $34(100 \%)$ & $184(100 \%)$ & $92(100 \%)$ & $335(100 \%)$ & $165(100 \%)$ \\
\hline $\begin{array}{l}\text { Plus thrombolysis or } \\
\text { thrombectomy, or both }\end{array}$ & 0 & 0 & $3(6 \%)$ & 0 & $4(6 \%)$ & $1(3 \%)$ & $13(7 \%)$ & $5(5 \%)$ & $20(6 \%)$ & $6(4 \%)$ \\
\hline \multicolumn{11}{|l|}{ Rivaroxaban formulation } \\
\hline Tablet & 0 & NA & $1(2 \%)$ & NA & $18(27 \%)$ & NA & $106(58 \%)$ & NA & $125(37 \%)$ & NA \\
\hline Suspension & $36(97 \%)$ & NA & $45(96 \%)$ & NA & $49(73 \%)$ & NA & $74(40 \%)$ & NA & $204(60 \%)$ & NA \\
\hline No study medication given & $1(3 \%)$ & NA & $1(2 \%)$ & NA & 0 & NA & $4(2 \%)$ & NA & $6(2 \%)$ & NA \\
\hline \multicolumn{11}{|l|}{ Standard anticoagulation group } \\
\hline Heparinst only & NA & $15(88 \%)$ & NA & $17(77 \%)$ & NA & $26(76 \%)$ & NA & $48(52 \%)$ & NA & $106(64 \%)$ \\
\hline $\begin{array}{l}\text { Heparins and vitamin } \mathrm{K} \\
\text { antagonist }\end{array}$ & NA & $2(12 \%)$ & NA & $5(23 \%)$ & NA & $8(24 \%)$ & NA & $41(45 \%)$ & NA & $56(34 \%)$ \\
\hline No study medication given & NA & 0 & NA & 0 & NA & 0 & NA & $3(3 \%)$ & NA & $3(2 \%)$ \\
\hline \multicolumn{11}{|l|}{ Study treatment duration, days } \\
\hline $\begin{array}{l}\text { 3-month intended study } \\
\text { period }\end{array}$ & $91(83-96)$ & $89(84-91)$ & $92(89-96)$ & $92(90-95)$ & $91(87-95)$ & $92(89-93)$ & $91(88-95)$ & $90(85-94)$ & $91(88-95)$ & $91(87-94)$ \\
\hline $\begin{array}{l}\text { 1-month intended study } \\
\text { period }\end{array}$ & $32(29-35)$ & $29(28-31)$ & NA & NA & NA & NA & NA & NA & NA & NA \\
\hline
\end{tabular}


first dose of study drug to 2 days after administration of last dose. Efficacy and safety outcomes were analysed by means of a Cox proportional hazards model, stratified according to index event (ie, cerebral vein or sinus thrombosis, catheter-related venous thromboembolism, and non-catheter-related venous thromboembolism). Absolute differences in risk with 95\% CIs were calculated. Kaplan-Meier curves were constructed to show the distribution of events over time. For the comparison of the ordered categories of change in thrombotic burden, the van Elteren test was used. ${ }^{25}$ Results are presented descriptively and are compared with the historical 3-month efficacy and safety results of a programme which evaluated rivaroxaban versus standard anticoagulation in 8282 adult patients with acute venous thromboembolism. ${ }^{9-11}$ Since young children might differ considerably from older children regarding demographics, clinical characteristics, risk factor profiles and treatment duration, we report these results for each age category separately without providing statistical analyses.

This trial is registered with ClinicalTrials.gov, number NCT02234843.

\section{Role of the funding source}

The funders contributed to study design, data collection, data analysis, data interpretation, writing of the report, and had the opportunity to review and comment on the manuscript before publication. Data were collected by the authors and their research teams. All authors had access to all study data and the first author had responsibility for the final version of the manuscript that was submitted.

\section{Results}

From Nov 14, 2014, to Sept 28, 2018, 500 (96\%) of 520 children from 107 paediatric hospitals in 28 countries (ie, Australia, Israel, Japan, and China, and countries in Europe, South America, and North America) passed the screen of eligibility criteria and were randomised (appendix pp 3-5). Nine (2\%) children did not take any study medication. One child in the standard anticoagulation group was lost to follow-up. Patient characteristics are in table 1.117 (23\%) had cerebral vein or sinus thrombosis (none catheter-related), 127 children $(25 \%)$ had catheter-related venous thromboembolism, and 256 (51\%) children had other, non-catheter-related venous thromboembolism (figure). Of the 127 children with catheter-related venous thromboembolism, 37 (29\%) were younger than 2 years of age and had a main treatment period of 1 month. The most frequent sites of venous thromboembolism involved the lower extremities (165 children, 33\%), cerebral veins or sinuses $(117,23 \%)$, lungs $(80,16 \%)$, upper extremities $(58,12 \%)$ and jugular vein $(52,10 \%)$. Venous thromboembolism was unprovoked in 56 children (11\%) and provoked by persistent risk factors (87 children [17\%]) or transient risk factors (236 [47\%]), or the combination of both (115 [23\%]; table 2). In the standard anticoagulation group, 106 children (64\%) received parenteral anticoagulation with heparins only.

After a median follow-up of 91 days (IQR 87-95) in children who had a study treatment period of 3 months $(\mathrm{n}=463)$ and 31 days (IQR 29-35) in children who had a study treatment period of 1 month $(n=37)$, symptomatic recurrent venous thromboembolism occurred in four $(1 \%)$ of the 335 children in the rivaroxaban group and in five $(3 \%)$ of the 165 children in the standard anticoagulation group (hazard ratio [HR] 0.40, 95\% CI 0.11 to 1.41 ; table 3 ), and an absolute difference in risk of 1.8 percentage points $(95 \% \mathrm{CI}-0.6$ to $6 \cdot 0)$. Fatal venous thromboembolism did not occur.

Repeat imaging showed improved clot resolution with rivaroxaban as compared with standard anticoagulation (test for ordered categories, $\mathrm{p}=0 \cdot 012$; table 4). Complete resolution of the index thrombosis occurred in 128 children (38\%) in the rivaroxaban group as compared with 43 children (26\%) in the standard anticoagulation group (odds ratio [OR], adjusted for index event, 1.70 [95\% CI 1.11-2.58]; $\mathrm{p}=0 \cdot 012$ ). Only one child in each treatment group had an asymptomatic deterioration (tables 3,4). The demographics and clinical characteristics of children with study outcomes are shown in the appendix $\mathrm{p} 13$

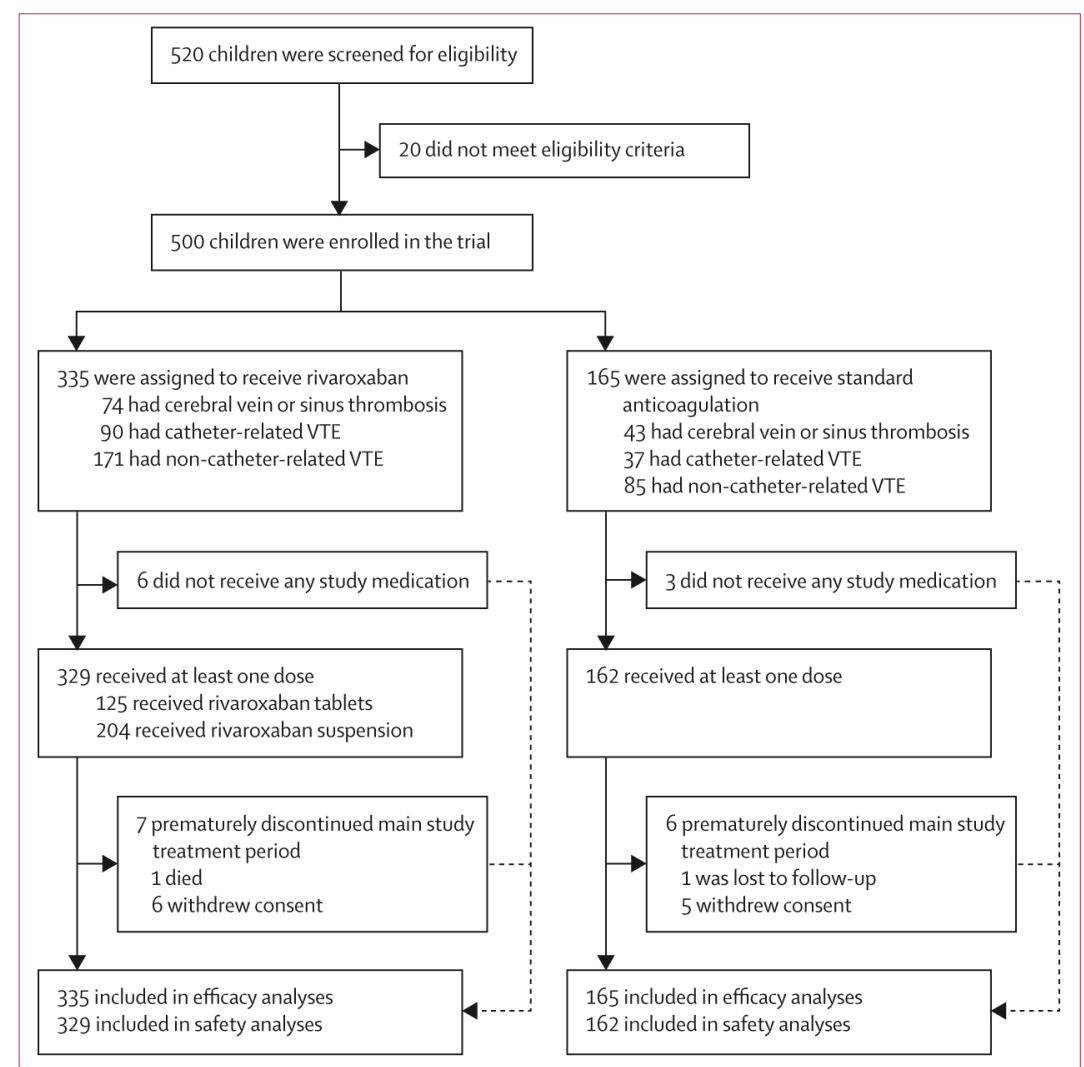

Figure: Trial profile

VTE=venous thromboembolism. 


\begin{tabular}{|c|c|c|c|c|c|c|c|c|c|c|}
\hline & \multicolumn{2}{|c|}{ Age birth-23 months } & \multicolumn{2}{|l|}{ Age 2-5years } & \multicolumn{2}{|c|}{ Age $6-11$ years } & \multicolumn{2}{|c|}{ Age $12-17$ years } & \multicolumn{2}{|l|}{ Total } \\
\hline & $\begin{array}{l}\text { Rivaroxaban } \\
(n=37)\end{array}$ & $\begin{array}{l}\text { Comparator } \\
(n=17)\end{array}$ & $\begin{array}{l}\text { Rivaroxaban } \\
(n=47)\end{array}$ & $\begin{array}{l}\text { Comparator } \\
(n=22)\end{array}$ & $\begin{array}{l}\text { Rivaroxaban } \\
(n=67)\end{array}$ & $\begin{array}{l}\text { Comparator } \\
(n=34)\end{array}$ & $\begin{array}{l}\text { Rivaroxaban } \\
(n=184)\end{array}$ & $\begin{array}{l}\text { Comparator } \\
(n=92)\end{array}$ & $\begin{array}{l}\text { Rivaroxaban } \\
(\mathrm{n}=335)\end{array}$ & $\begin{array}{l}\text { Comparator } \\
(n=165)\end{array}$ \\
\hline \multicolumn{11}{|c|}{ Cause of index venous thromboembolism } \\
\hline Provoked by persistent risk factor & $2(5 \%)$ & $1(6 \%)$ & $5(11 \%)$ & $2(9 \%)$ & $18(27 \%)$ & $4(12 \%)$ & $37(20 \%)$ & $18(20 \%)$ & $62(19 \%)$ & $25(15 \%)$ \\
\hline Provoked by transient risk factor & $15(41 \%)$ & $8(47 \%)$ & $26(55 \%)$ & $15(68 \%)$ & $30(45 \%)$ & $23(68 \%)$ & $80(43 \%)$ & $39(42 \%)$ & $151(45 \%)$ & $85(52 \%)$ \\
\hline $\begin{array}{l}\text { Provoked by persistent and transient } \\
\text { risk factor }\end{array}$ & $18(49 \%)$ & $6(35 \%)$ & $14(30 \%)$ & $3(14 \%)$ & $17(25 \%)$ & $4(12 \%)$ & $41(22 \%)$ & $12(13 \%)$ & $90(27 \%)$ & $25(15 \%)$ \\
\hline Unprovoked & $2(5 \%)$ & $1(6 \%)$ & $1(2 \%)$ & $1(5 \%)$ & $2(3 \%)$ & $1(3 \%)$ & $26(14 \%)$ & $22(24 \%)$ & $31(9 \%)$ & $25(15 \%)$ \\
\hline Not applicable or unknown & 0 & $1(6 \%)$ & $1(2 \%)$ & $1(5 \%)$ & 0 & $2(6 \%)$ & 0 & $1(1 \%)$ & $1(<1 \%)$ & $5(3 \%)$ \\
\hline \multicolumn{11}{|c|}{ Provoked venous thromboembolism, number of risk factors } \\
\hline 1 & $8(22 \%)$ & $5(29 \%)$ & $20(43 \%)$ & $8(36 \%)$ & $36(54 \%)$ & $23(68 \%)$ & $94(51 \%)$ & $46(50 \%)$ & $158(47 \%)$ & $82(50 \%)$ \\
\hline 2 & $19(51 \%)$ & $3(18 \%)$ & $17(36 \%)$ & $10(45 \%)$ & $24(36 \%)$ & $7(21 \%)$ & $49(27 \%)$ & $17(18 \%)$ & $109(33 \%)$ & $37(22 \%)$ \\
\hline$>2$ & $8(22 \%)$ & $7(41 \%)$ & $8(17 \%)$ & $2(9 \%)$ & $5(7 \%)$ & $1(3 \%)$ & $15(8 \%)$ & $6(7 \%)$ & $34(10 \%)$ & $15(9 \%)$ \\
\hline \multicolumn{11}{|c|}{ Provoked venous thromboembolism, type of risk factor } \\
\hline Active cancer* & $1(3 \%)$ & 0 & $9(19 \%)$ & $2(9 \%)$ & $10(15 \%)$ & $5(15 \%)$ & $20(11 \%)$ & $9(10 \%)$ & $40(12 \%)$ & $16(10 \%)$ \\
\hline Haematological cancer & $1(3 \%)$ & 0 & $5(11 \%)$ & $2(9 \%)$ & $7(10 \%)$ & $3(9 \%)$ & $12(7 \%)$ & $6(7 \%)$ & $25(7 \%)$ & $11(7 \%)$ \\
\hline Solid tumour & 0 & 0 & $4(9 \%)$ & 0 & $3(4 \%)$ & $2(6 \%)$ & $8(4 \%)$ & $3(3 \%)$ & $15(4 \%)$ & $5(3 \%)$ \\
\hline Major organ disease & $18(49 \%)$ & $16(94 \%)$ & $10(21 \%)$ & $3(14 \%)$ & $17(25 \%)$ & $2(6 \%)$ & $18(10 \%)$ & $9(10 \%)$ & $63(19 \%)$ & $20(12 \%)$ \\
\hline Cardiac & $15(41 \%)$ & $6(35 \%)$ & $8(17 \%)$ & $2(9 \%)$ & $6(9 \%)$ & $1(3 \%)$ & $6(3 \%)$ & $5(5 \%)$ & $35(10 \%)$ & $14(8 \%)$ \\
\hline Gastrointestinal & 0 & 0 & 0 & 0 & 0 & 0 & $3(2 \%)$ & $1(1 \%)$ & $3(1 \%)$ & $1(1 \%)$ \\
\hline Renal & $2(5 \%)$ & 0 & 0 & $1(5 \%)$ & $9(13 \%)$ & 0 & $5(3 \%)$ & $1(1 \%)$ & $16(5 \%)$ & $2(1 \%)$ \\
\hline Neurological & $1(3 \%)$ & 0 & $2(4 \%)$ & 0 & $2(3 \%)$ & $1(3 \%)$ & $4(2 \%)$ & $2(2 \%)$ & $9(3 \%)$ & $3(2 \%)$ \\
\hline Major congenital venous anomaly & 0 & $1(6 \%)$ & 0 & 0 & $4(6 \%)$ & $1(3 \%)$ & $5(3 \%)$ & $3(3 \%)$ & $9(3 \%)$ & $5(3 \%)$ \\
\hline Known inherited thrombophilia & $2(5 \%)$ & 0 & $2(4 \%)$ & 0 & $4(6 \%)$ & 0 & $19(10 \%)$ & $5(5 \%)$ & $27(8 \%)$ & $5(3 \%)$ \\
\hline $\begin{array}{l}\text { Antithrombin, protein C, or protein S } \\
\text { deficiency }\end{array}$ & $1(3 \%)$ & 0 & $1(2 \%)$ & 0 & $3(4 \%)$ & 0 & $10(5 \%)$ & $2(2 \%)$ & $15(4 \%)$ & $2(1 \%)$ \\
\hline $\begin{array}{l}\text { Factor } V \text { Leiden or prothrombin } \\
\text { mutation }\end{array}$ & $1(3 \%)$ & 0 & $1(2 \%)$ & 0 & $1(1 \%)$ & 0 & $9(5 \%)$ & $3(3 \%)$ & $12(4 \%)$ & $3(2 \%)$ \\
\hline Acquired thrombophilia† & 0 & 0 & 0 & 0 & $2(3 \%)$ & 0 & $6(3 \%)$ & $2(2 \%)$ & $8(2 \%)$ & $2(1 \%)$ \\
\hline Family history of venous thrombosis $\ddagger$ & 0 & 0 & 0 & 0 & 0 & 0 & $5(3 \%)$ & $2(2 \%)$ & $5(1 \%)$ & $2(1 \%)$ \\
\hline Morbid obesity & 0 & 0 & 0 & 0 & 0 & 0 & $14(8 \%)$ & $4(4 \%)$ & $14(4 \%)$ & $4(2 \%)$ \\
\hline Major surgery or trauma & $12(32 \%)$ & $6(35 \%)$ & $13(28 \%)$ & $9(41 \%)$ & $18(27 \%)$ & $9(26 \%)$ & $35(19 \%)$ & $18(20 \%)$ & $78(23 \%)$ & $42(25 \%)$ \\
\hline Major infectious disease & $11(30 \%)$ & $10(59 \%)$ & $25(53 \%)$ & $12(55 \%)$ & $28(42 \%)$ & $15(44 \%)$ & $32(17 \%)$ & $9(10 \%)$ & $96(29 \%)$ & $46(28 \%)$ \\
\hline Venous catheter & $26(70 \%)$ & $10(59 \%)$ & $19(40 \%)$ & $7(32 \%)$ & $16(24 \%)$ & $8(24 \%)$ & $29(16 \%)$ & $11(12 \%)$ & $90(27 \%)$ & $36(22 \%)$ \\
\hline Prolonged immobilisation & 0 & 0 & 0 & $1(5 \%)$ & $1(1 \%)$ & 0 & $2(1 \%)$ & $2(2 \%)$ & $3(1 \%)$ & $3(2 \%)$ \\
\hline Use of oestrogens or progestins & 0 & 0 & 0 & 0 & 0 & 0 & $53 / 97(55 \%) \S$ & $24 / 55(44 \%) \S$ & $53(16 \%)$ & $24(15 \%)$ \\
\hline
\end{tabular}

Clinically relevant bleeding was observed in ten (3\%) of the 329 rivaroxaban recipients (all were non-major) and in three $(2 \%)$ of the 162 standard anticoagulation recipients (two major and one non-major [HR 1.58, 95\% CI 0.51 to $6 \cdot 27$ ]; table 3 ), an absolute difference in risk of 1.2 percentage points (95\% CI $-2 \cdot 8$ to $4 \cdot 0$ ). The major bleeding events presented as an intracranial and pulmonary bleeding. The composite of recurrent venous thromboembolism or major bleeding occurred in four $(1 \%)$ of 335 children in the rivaroxaban group and seven (4\%) of 165 children in the standard anticoagulation group (HR 0.30 [0.08 to 0.93$])$. The death of a single child in the rivaroxaban group was due to cancer progression. The most frequent adverse events during the main study treatment period are listed in table 5 , and a full list of adverse events is provided in appendix p 13-16.

In the rivaroxaban group, the upper margins of the 95\% CIs of the incidences of recurrent venous thromboembolism, major bleeding, net clinical benefit, and mortality were comparable with results observed in adults (appendix p 17). ${ }^{9-11}$ Although the point estimate of the HR of the relative treatment effect of rivaroxaban versus standard anticoagulants was more favourable in children than in adults (ie, 0.40 vs 0.82 ), the upper margin of the $95 \%$ CI was slightly higher in children (ie, 1.41 vs 1.13). The Kaplan-Meier curves of recurrent venous thromboembolism and clinically relevant bleeding events in children who received 


\begin{tabular}{|c|c|c|c|}
\hline & Rivaroxaban & Comparator & Hazard ratio $(95 \% \mathrm{Cl})$ \\
\hline \multicolumn{4}{|l|}{ Efficacy population } \\
\hline Participants assessed & 335 & 165 & .. \\
\hline Primary efficacy outcome & $4(1 \%)$ & $5(3 \%)$ & $0.40(0.11-1.41)$ \\
\hline Cerebral vein and sinus thrombosis & 0 & 1 & .. \\
\hline Catheter-related venous thromboembolism & 0 & 0 & .. \\
\hline Non-catheter-related venous thromboembolism & 4 & 4 & \\
\hline Primary efficacy outcome or deterioration on repeat imaging & $5(1 \%)$ & $6(4 \%)$ & $0.41(0.12-1 \cdot 36)$ \\
\hline Primary efficacy outcome or major bleeding & $4(1 \%)$ & $7(4 \%)$ & $0.30(0.08-0.93)$ \\
\hline Mortality & $1(<1 \%)$ & 0 &.. \\
\hline Cancer-related & 1 & 0 &. \\
\hline \multicolumn{4}{|l|}{ Safety population } \\
\hline Participants assessed & 329 & 162 &.. \\
\hline Major or clinically relevant non-major bleeding & $10(3 \%)$ & $3(2 \%)$ & $1.58(0.51-6 \cdot 27)$ \\
\hline Major bleeding & 0 & $2(1 \%)$ &.. \\
\hline Pulmonary & 0 & 1 & .. \\
\hline Intracranial & 0 & 1 &.. \\
\hline Clinically relevant non-major bleeding & $10(3 \%)$ & $1(1 \%)$ & .. \\
\hline Gastrointestinal & 4 & 0 &.. \\
\hline Urogenital & 2 & 0 & .. \\
\hline Skin & 1 & 0 &.. \\
\hline Nasal or mouth & 3 & 1 &.. \\
\hline
\end{tabular}

\begin{tabular}{|c|c|c|c|c|c|c|c|c|c|c|}
\hline & \multicolumn{2}{|c|}{ Age birth-23 months } & \multicolumn{2}{|c|}{ Age $2-5$ years } & \multicolumn{2}{|c|}{ Age 6-11 years } & \multicolumn{2}{|c|}{ Age $12-17$ years } & \multicolumn{2}{|l|}{ Total } \\
\hline & $\begin{array}{l}\text { Rivaroxaban } \\
(\mathrm{n}=37)\end{array}$ & $\begin{array}{l}\text { Comparator } \\
(\mathrm{n}=17)\end{array}$ & $\begin{array}{l}\text { Rivaroxaban } \\
(n=47)\end{array}$ & $\begin{array}{l}\text { Comparator } \\
(\mathrm{n}=22)\end{array}$ & $\begin{array}{l}\text { Rivaroxaban } \\
(n=67)\end{array}$ & $\begin{array}{l}\text { Comparator } \\
(\mathrm{n}=34)\end{array}$ & $\begin{array}{l}\text { Rivaroxaban } \\
(\mathrm{n}=184)\end{array}$ & $\begin{array}{l}\text { Comparator } \\
(n=92)\end{array}$ & $\begin{array}{l}\text { Rivaroxaban } \\
(n=335)\end{array}$ & $\begin{array}{l}\text { Comparator } \\
(n=165)\end{array}$ \\
\hline Normalised & $16(43 \%)$ & $5(29 \%)$ & $17(36 \%)$ & $6(27 \%)$ & $28(42 \%)$ & $8(24 \%)$ & $67(36 \%)$ & $24(26 \%)$ & $128(38 \%)$ & $43(26 \%)$ \\
\hline Improved & $10(27 \%)$ & $7(41 \%)$ & $18(38 \%)$ & $9(41 \%)$ & $27(40 \%)$ & $16(47 \%)$ & $74(40 \%)$ & $43(47 \%)$ & $129(39 \%)$ & $75(45 \%)$ \\
\hline Uncertain & $10(27 \%)$ & $2(12 \%)$ & $9(19 \%)$ & $4(18 \%)$ & $8(12 \%)$ & $5(15 \%)$ & $30(16 \%)$ & $17(18 \%)$ & $57(17 \%)$ & $28(17 \%)$ \\
\hline No relevant change & $1(3 \%)$ & $3(18 \%)$ & $2(4 \%)$ & $2(9 \%)$ & $4(6 \%)$ & $4(12 \%)$ & $9(5 \%)$ & $4(4 \%)$ & $16(5 \%)$ & $13(8 \%)$ \\
\hline Deterioration & 0 & 0 & $1(2 \%)$ & 0 & 0 & 0 & 0 & $1(1 \%)$ & $1(<1 \%)$ & $1(<1 \%)$ \\
\hline $\begin{array}{l}\text { Symptomatic recurrent venous } \\
\text { thromboembolism }\end{array}$ & 0 & 0 & 0 & $1(5 \%)$ & 0 & $1(3 \%)$ & $4(2 \%)$ & $3(3 \%)$ & $4(1 \%)$ & $5(3 \%)$ \\
\hline
\end{tabular}

rivaroxaban were superimposable with those in adults (appendix p 18, 19).

\section{Discussion}

In children of all ages with various manifestations of venous thromboembolism, treatment with bodyweightadjusted rivaroxaban, targeting the therapeutic exposure range of young adults, resulted in a low risk of recurrent venous thromboembolism and clinically relevant bleeding, similar to standard therapy. Moreover, treatment with rivaroxaban resulted in a greater reduction of thrombus mass as compared with standard therapy at repeat imaging. Study outcome rates and relative efficacy and safety of rivaroxaban were similar to findings from previous randomised trials evaluating rivaroxaban versus standard anticoagulants in adults with venous thromboembolism.

The study could not be powered to independently show non-inferiority for efficacy of rivaroxaban in comparison to standard therapy in children; therefore, interpretation of the results relies in part on extrapolation of data obtained with rivaroxaban in adults. As a prerequisite for extrapolation according to FDA and European Medicines Agency paediatric guidelines, ${ }^{27,28}$ on the basis of comparison of the results of this paediatric study with those of large randomised studies in adults, ${ }^{9-11}$ we deduce a similar clinical course of venous thromboembolism, and similar relative treatment effects. The upper margin of the $95 \%$ CI of the HR for the main efficacy outcome of the comparison of 


\begin{tabular}{|c|c|c|c|c|c|c|}
\hline & \multicolumn{3}{|c|}{ Rivaroxaban ( $n=329)$} & \multicolumn{3}{|c|}{ Standard anticoagulants ( $n=162)$} \\
\hline & Grade 1-2 & Grade 3 & Grade 4 & Grade 1-2 & Grade 3 & grade 4 \\
\hline Any event & $231(70 \%)$ & $39(12 \%)$ & $4(1 \%)$ & $100(62 \%)$ & $23(14 \%)$ & $1(1 \%)$ \\
\hline Blood and lymphatic system disorders & $29(9 \%)$ & $8(2 \%)$ & $1(<1 \%)$ & $12(7 \%)$ & $4(2 \%)$ & 0 \\
\hline Bone marrow failure & $2(<1 \%)$ & 0 & $1(<1 \%)$ & 0 & 0 & 0 \\
\hline Febrile neutropenia & $3(1 \%)$ & $7(2 \%)$ & 0 & 0 & $1(1 \%)$ & 0 \\
\hline Thrombocytopenia & $10(3 \%)$ & $4(1 \%)$ & 0 & $2(1 \%)$ & 0 & 0 \\
\hline Cardiac disorders & $8(2 \%)$ & $1(<1 \%)$ & $1(<1 \%)$ & $4(2 \%)$ & $2(1 \%)$ & 0 \\
\hline Low cardiac output syndrome & 0 & 0 & $1(<1 \%)$ & 0 & 0 & 0 \\
\hline Pericardial haemorrhage & 0 & 0 & $1(<1 \%)$ & 0 & 0 & 0 \\
\hline Eye disorders & $18(5 \%)$ & 0 & 0 & $7(4 \%)$ & 0 & 0 \\
\hline Gastrointestinal disorders & $101(31 \%)$ & $9(3 \%)$ & 0 & $44(27 \%)$ & $1(1 \%)$ & 0 \\
\hline Abdominal pain & $17(5 \%)$ & $2(1 \%)$ & 0 & $8(5 \%)$ & $1(1 \%)$ & 0 \\
\hline Constipation & $10(3 \%)$ & 0 & 0 & $12(7 \%)$ & 0 & 0 \\
\hline Diarrhoea & $22(7 \%)$ & $2(1 \%)$ & 0 & $9(6 \%)$ & 0 & 0 \\
\hline Nausea & $21(6 \%)$ & 0 & 0 & $7(4 \%)$ & 0 & 0 \\
\hline Vomiting & $31(9 \%)$ & $4(1 \%)$ & 0 & $13(8 \%)$ & 0 & 0 \\
\hline General disorders and administration site conditions & $74(22 \%)$ & $7(2 \%)$ & 0 & $51(31 \%)$ & $1(1 \%)$ & 0 \\
\hline Fatigue & $18(5 \%)$ & $2(1 \%)$ & 0 & $6(4 \%)$ & 0 & 0 \\
\hline Pyrexia & $35(11 \%)$ & 0 & 0 & $13(8 \%)$ & 0 & 0 \\
\hline Infections and infestations & $110(33 \%)$ & $5(2 \%)$ & $1(<1 \%)$ & $44(27 \%)$ & $5(3 \%)$ & 0 \\
\hline Nasopharyngitis & $25(8 \%)$ & 0 & 0 & $8(5 \%)$ & 0 & 0 \\
\hline Sepsis & 0 & 0 & $1(<1 \%)$ & 0 & 0 & 0 \\
\hline Injury, poisoning, and procedural complications & $74(22 \%)$ & $4(1 \%)$ & 0 & $27(17 \%)$ & $3(2 \%)$ & $1(1 \%)$ \\
\hline Contusion & $14(4 \%)$ & 0 & 0 & $10(6 \%)$ & 0 & 0 \\
\hline Subdural haemorrhage & 0 & 0 & 0 & 0 & 0 & $1(1 \%)$ \\
\hline Investigations & $27(8 \%)$ & $9(3 \%)$ & $1(<1 \%)$ & $17(10 \%)$ & $5(3 \%)$ & 0 \\
\hline Alanine aminotransferase increased & $4(1 \%)$ & $3(1 \%)$ & 0 & $4(2 \%)$ & $3(2 \%)$ & 0 \\
\hline Hepatic enzyme increased & $2(1 \%)$ & $1(<1 \%)$ & $1(<1 \%)$ & 0 & 0 & 0 \\
\hline Platelet count decreased & $6(2 \%)$ & $3(1 \%)$ & 0 & $2(1 \%)$ & 0 & 0 \\
\hline Metabolism and nutrition disorders & $26(8 \%)$ & $1(<1 \%)$ & 0 & $7(4 \%)$ & 0 & 0 \\
\hline Musculoskeletal and connective tissue disorders & $52(16 \%)$ & $4(1 \%)$ & 0 & $19(12 \%)$ & 0 & 0 \\
\hline Pain in extremity & $22(7 \%)$ & $2(1 \%)$ & 0 & $8(5 \%)$ & 0 & 0 \\
\hline $\begin{array}{l}\text { Neoplasms benign, malignant, and unspecified (including cysts } \\
\text { and polyps) }\end{array}$ & $1(<1 \%)$ & 0 & 0 & $1(1 \%)$ & $2(1 \%)$ & 0 \\
\hline Nervous system disorders & $78(24 \%)$ & $5(2 \%)$ & 0 & $34(21 \%)$ & $4(2 \%)$ & 0 \\
\hline Headache & $56(17 \%)$ & $1(<1 \%)$ & 0 & $22(14 \%)$ & $2(1 \%)$ & 0 \\
\hline Reproductive system and breast disorders & $27(8 \%)$ & $2(1 \%)$ & 0 & $13(8 \%)$ & 0 & 0 \\
\hline Menorrhagia & $23(7 \%)$ & 0 & 0 & $5(3 \%)$ & 0 & 0 \\
\hline Respiratory, thoracic, and mediastinal disorders & $78(24 \%)$ & $2(1 \%)$ & $1(<1 \%)$ & $33(20 \%)$ & $1(1 \%)$ & 0 \\
\hline Cough & $16(5 \%)$ & 0 & 0 & $10(6 \%)$ & 0 & 0 \\
\hline Epistaxis & $38(12 \%)$ & 0 & 0 & $18(11 \%)$ & 0 & 0 \\
\hline Respiratory failure & 0 & 0 & $1(<1 \%)$ & 0 & 0 & 0 \\
\hline Skin and subcutaneous tissue disorders & $61(19 \%)$ & 0 & 0 & $25(15 \%)$ & $1(1 \%)$ & 0 \\
\hline \multicolumn{7}{|c|}{$\begin{array}{l}\text { Data are } n(\%) \text { of events (as defined by the Medical Dictionary for Regulatory Activities). }{ }^{26} \text { Data shown for all randomised patients who received at least one dose of treatment } \\
\text { All grade } 4-5 \text { events are shown, but grade } 3 \text { events are shown if they occurred in at least three (1\%) children in the rivaroxaban group and at least two (1\%) children in the } \\
\text { standard anticoagulant group. Grade } 1-2 \text { events are only shown if there were grade } 3 \text { or worse events. Grade } 1-2 \text { events would also have been shown had they occurred in } \\
\text { least } 5 \% \text { of children. A single grade } 5 \text { event occurred (myxofibrosarcoma in the rivaroxaban group), which was not treatment related. }\end{array}$} \\
\hline
\end{tabular}

rivaroxaban with standard anticoagulants was 1.41. In rivaroxaban treatment studies in adults, ${ }^{9-11}$ a noninferiority margin of 1.75 was accepted because this margin preserves at least $75 \%$ of the established treatment effect of standard anticoagulant therapy. ${ }^{29}$ By use of this margin, or even the more stringent margin of 1.50 which was used in the venous thromboembolism treatment study with edoxaban, ${ }^{30}$ bodyweight-adjusted 
rivaroxaban treatment could be considered to be noninferior to standard anticoagulants in children.

Certain features of the study require comment. First, we believe that the trial population is representative of the paediatric population with venous thromboembolism, since the broad range of manifestations of venous thromboembolism typically observed in paediatric practice were included and a short list of ineligibility criteria was applied. Approximately $90 \%$ of children had venous thromboembolism secondary to underlying disorders associated with hypercoagulable states such as cancer, trauma or surgery, major organ disease, thrombophilia and infection, while many had multiples of these risk factors. The proportion is distinctly different from the distribution of risk factors in adults in whom approximately half of the patients present with unprovoked venous thromboembolism, ${ }^{31}$ but is consistent with the known epidemiology of thrombosis in children. ${ }^{2-5,8,22}$ Second, the use of an open-label design is a potential weakness, but long-term administration of placebo injections and blood samples for sham laboratory monitoring in children randomised to rivaroxaban was considered to be neither ethical nor feasible. Hence, observer bias was limited by requiring objective tests when recurrent venous thromboembolism was suspected and by use of an independent adjudication committee unaware of study treatment assignment. Third, in adults, rivaroxaban is started without initial heparinisation and administered in a dose of $15 \mathrm{mg}$ twice-daily for 3 weeks followed by $20 \mathrm{mg}$ once-daily. Since many children with venous thromboembolism are referred from peripheral centres to more specialised centres and the process of obtaining informed consent in children is notoriously time consuming, most potentially eligible children had already received initial heparin treatment for several days. Therefore, we decided to deviate from the rivaroxaban regimen in adults and elected for an initial course of at least 5 days of heparinisation followed by rivaroxaban.

What are the clinical implications of this study's observations? We think physicians will have the option to treat children with bodyweight-adjusted oral rivaroxaban regimens, administered as tablet or suspension, without requiring regular laboratory monitoring and dose adjustments. Such anticoagulant regimens, validated in the paediatric venous thromboembolism population, obviate the need for manipulation of adult dosage forms, and substantially reduce the number of injections needed for standard anticoagulation treatment and associated blood sampling. Thus, the paediatric rivaroxaban regimens represent an advantageous alternative treatment for children with venous thromboembolism.

In summary, in children with acute venous thromboembolism, treatment with rivaroxaban in bodyweightadjusted 20 mg-equivalent dose regimens resulted in a similar low risk of recurrent venous thromboembolism and improved clot resolution without increased bleeding, as compared with standard anticoagulation. Study outcomes and relative efficacy and safety of rivaroxaban in children were similar to those observed in adults.

Contributors

CM, AWAL, AKCC, GK, MPM, GY, and PM designed the study. All authors contributed to data collection, data analysis, and data interpretation. All authors contributed to the writing of the manuscript, approved the final version, and agree to be accountable for all aspects of the report.

\section{Declaration of interests}

CM reports receiving personal fees and fees, paid to his institution, from Bayer, Bristol-Myers-Squibb, Pfizer and fees, paid to his institution, from Boehringer Ingelheim. AWAL being employed by Bayer. RK receiving personal fees from Bayer, CSL Behring, and Kedrion. DB receiving personal fees and grant support from Actelion Pharmaceuticals, Bayer, Eli Lilly, BMS, and Novartis and grant support from AbbVie. PC receiving personal fees from Onyx Health Limited. AKCC receiving personal fees from Bayer and fees, paid to his institution, from Bayer, Pfizer, Daiichi Sankyo, and Bristol-Myers-Squibb. GK receiving personal fees from Bayer, Boehringer Ingelheim, and Daiichi Sankyo and fees, paid to her institution from Pfizer. SH receiving personal fees and fees, paid to her institution, from Bayer, Pfizer, and Daiichi Sankyo. AS receiving personal fees from Bayer, Pfizer, Daiichi Sankyo and Boehringer Ingelheim. PA receiving personal fees and fees, paid to his institution, from Abbvie and Bayer, and fees paid to his institution from Actelion, Novartis, and Daiichi Sankyo. EC receiving personal fees from Boehringer Ingelheim and Bristol Myers-Squibb, and fees, paid to her institution from Bayer Pfizer, and Daiichi Sankyo. DLY receiving fees, paid to his institution, from Bayer, Pfizer, and Bristol-Myers Squibb. OL receiving personal fees from Bayer, Pfizer, Boehringer Ingelheim, and Novartis, and fees, paid to her institution, from Bayer. JB-W receiving personal fees and fees, paid to his institution, from Bayer, Daiichi Sankyo, DOASENSE and Portola and fees, paid to his institution, from Pfizer. TTB receiving fees from Boehringer Ingelheim and Bayer, and grant support from Leo Pharma. IM receiving fees from Sanofi and Bayer. MP receiving grant support from Pfizer and Sobi. MPM receiving personal fees from Bayer. GY receiving personal fees from GlaxoSmithKline and Portola and personal fees and fees, paid to his institution, from Bayer and Daiichi Sankyo. AFP, MM, WTS, SDB, KT, DK being employed by Bayer. JFH was employed by Bayer. $\mathrm{MC}$ receiving grant support from and serving on a data and safety monitoring board for Bayer, receiving advisory board fees from Shionogi, Octapharma, Bristol-Myers Squibb Canada, and Asahi Kasei, receiving educational funding from Alexion Pharmaceuticals, Pfizer, CSL Behring, and Diagnostica Stago, receiving grant support, paid to his institution, from Leo Pharma, serving on a data and safety monitoring board for Daiichi Sankyo, owning stock in Alnylam Pharmaceuticals, and receiving educational funding and advisory board fees from Servier Canada. MHP receiving personal fees from Bayer. No other potential conflict of interest relevant to this article was reported.

\section{References}

1 Macartney CA, Chan AKC. Thrombosis in children. Semin Thromb Hemost 2011; 37: 763.

2 Raffini L, Huang YS, Witmer C, Feudtner C. Dramatic increase in venous thromboembolism in children's hospitals in the United States from 2001 to 2007. Pediatrics 2009; 124: 1001-08.

3 Tuckuviene R, Christensen AL, Helgestad J, Johnsen SP, Kristensen SR. Pediatric venous and arterial noncerebral thromboembolism in Denmark: a nationwide population-based study. J Pediatr 2011; 159: 663-69.

4 van Ommen $\mathrm{CH}$, Heijboer $\mathrm{H}$, Büller HR, Hirasing RA, Heijmans HS, Peters M. Venous thromboembolism in childhood: a prospective two-year registry in The Netherlands. I Pediatr 2001; 139: 676-81.

5 Stein PD, Kayali F, Olson RE. Incidence of venous thromboembolism in infants and children: data from the Nationa Hospital Discharge Survey. J Pediatr 2004; 145: 563-65.

6 Raskob GE, Angchaisuksiri P, Blanco AN, et al. Thrombosis: a major contributor to global disease burden. Thromb Res 2014; 134: $931-38$ 
7 Massicotte P, Julian JA, Gent M, et al. An open-label randomized controlled trial of low molecular weight heparin compared to heparin and coumadin for the treatment of venous thromboembolic events in children: the REVIVE trial. Thromb Res 2003; 109: 85-92.

8 Monagle P, Cuello CA, Augustine C, et al. American Society of Hematology 2018 Guidelines for management of venous thromboembolism: treatment of pediatric venous thromboembolism. Blood Adv 2018; 2: 3292-316.

9 Bauersachs R, Berkowitz SD, Brenner B, et al. Oral rivaroxaban for symptomatic venous thromboembolism. N Engl J Med 2010; 363: 2499-510.

10 Büller HR, Prins MH, Lensin AW, et al. Oral rivaroxaban for the treatment of symptomatic pulmonary embolism. N Engl J Med 2012; 366: 1287-97.

11 Prins $\mathrm{MH}$, Lensing AW, Bauersachs R, et al. Oral rivaroxaban versus standard therapy for the treatment of symptomatic venous thromboembolism: a pooled analysis of the EINSTEIN-DVT and PE randomized studies. Thromb J 2013; 11: 21.

12 European Medicines Agency. Rivaroxaban Paediatric Investigation Plan, 2017. http://www.ema.europa.eu/docs/en_GB/document_ library/PIP_decision/WC500232013.pdf (accessed April 26, 2019).

13 FDA list of pediatric written requests issued. https://www.fda.gov/ Drugs/DevelopmentApprovalProcess/DevelopmentResources/ ucm050002.htm (accessed April 26, 2019).

14 Attard C, Monagle P, Kubitza D, Ignjatovic V. The in vitro anticoagulant effect of rivaroxaban in children. Thromb Res 2012; 130: 804-07.

15 Attard C, Monagle P, Kubitza D, Ignjatovic V. The in-vitro anticoagulant effect of rivaroxaban in neonates. Blood Coagul Fibrinolysis 2014; 25: 237-40.

16 Willmann S, Becker C, Burghaus R, et al. Development of a paediatric population-based model of the pharmacokinetics of rivaroxaban. Clin Pharmacokinet 2014; 53: 89-102.

17 Kubitza D, Willmann S, Becka M, et al. Exploratory evaluation of pharmacodynamics, pharmacokinetics and safety of rivaroxaban in children and adolescents: an EINSTEIN-Jr phase I study. Thromb J 2018; $16: 31$.

18 Monagle $\mathrm{P}$, Lensing AWA, Thelen K, et al. Bodyweight-adjusted rivaroxaban in children with venous thromboembolism. An Einstein-Jr. phase II evaluation. Lancet Haematol 2019; 6: e500-09.

19 Willmann S, Zhang L, Frede M, et al. Integrated population pharmacokinetic analysis of rivaroxaban across multiple patient populations. CPT Pharmacometrics Syst Pharmacol 2018; 7: 309-20.
20 Richey RH, Hughes C, Craig JV, et al. A systematic review of the use of dosage form manipulation to obtain required doses to inform use of manipulation in paediatric practice. Int J Pharm 2017; 518: 155-66.

21 Chan A, Lensing AWA, Kubitza D, et al. Clinical presentation and therapeutic management of venous thrombosis in young children: a retrospective analysis. Thromb J 2018; 16: 29.

22 Lensing AWA, Male C, Young G, et al. Rivaroxaban versus standard anticoagulation for acute venous thromboembolism in childhood. Design of the EINSTEIN-Jr phase III study. Thromb J 2018; 16: 34.

23 Schulman S, Kearon C. Definition of major bleeding in clinical investigations of antihemostatic medicinal products in non-surgical patients. J Thromb Haemost 2005; 3: 692-94.

24 Kaatz S, Ahmad D, Spyropoulos AC, Schulman S. Definition of clinically relevant non-major bleeding in studies of anticoagulants in atrial fibrillation and venous thromboembolic disease in non-surgical patients: communication from the SSC of the ISTH. J Thromb Haemost 2015; 13: 2119-26.

25 van Elteren $\mathrm{PH}$. On the combination of independent two-sample tests of Wilcoxon. Bull Int Stat Inst 1960; 37: 351-61.

26 Medical dictionary for regulatory activities. https://www.meddra. org/how-to-use/support-documentation/english (accessed Oct 26, 2019)

27 European Medicines Agency. Reflection paper on extrapolation of efficacy and safety in paediatric medicine development. https:// www.ema.europa.eu/en/documents/scientific-guideline/adoptedreflection-paper-use-extrapolation-development-medicinespaediatrics-revision-1_en.pdf (accessed April 26, 2019).

28 Sun H, Temeck J, Chambers W, Perkins G, Bonnel R, Murphy D. Extrapolation of efficacy in pediatric drug development and evidence-based medicine: progress and lessons learned. Ther Innov Regul Sci 2018; 52: 199-205.

29 Prins $\mathrm{MH}$, Lensing AW. Derivation of the non-inferiority margin for the evaluation of direct oral anticoagulants in the treatment of venous thromboembolism. Thromb J 2013; 11: 13-18.

30 Büller HR, Décousus H, Grosso MA, et al. Edoxaban versus warfarin for the treatment of symptomatic venous thromboembolism. N Engl J Med 2013; 369: 1406-15.

31 Prins MH, Lensing AWA, Prandoni P, et al. Risk of recurrent venous thromboembolism according to baseline risk factor profiles. Blood Adv 2018; 2: 788-96. 